\title{
Cardiopulmonary Exercise Testing: The ABC for the Clinical Cardiologist
}

\author{
Helen Triantafyllidi Dionyssia Birmpa Dimitrios Benas Paraskevi Trivilou \\ Anastasia Fambri Efstathios K. Iliodromitis \\ 2nd Department of Cardiology, National and Kapodistrian University of Athens, Medical School, ATTIKON Hospital, \\ Athens, Greece
}

\section{Keywords}

Cardiopulmonary exercise testing · Oxygen consumption · Heart failure

\section{Abstract}

Background: Cardiopulmonary exercise testing (CPET) is the most comprehensive technique which allows a holistic approach to cardiopulmonary diseases. Summary: This article provides basic information addressed to the Clinical Cardiologist regarding the utility and the indications of the CPET technique in the everyday clinical practice. Clinical application of CPET continues to evolve and protocols should be adapted to each specific patient to obtain the most reliable and useful information. Key Messages: Clinical Cardiologists with an interest over CPET may become familiar with this exercise method and its main measured variables, refresh their knowledge regarding the underlying pathophysiological mechanisms of oxygen transport chain, learn how to interpret the CPET results and promote appropriate patient referrals to experts.

(c) 2021 S. Karger AG, Basel

\section{Introduction}

Cardiopulmonary exercise testing (CPET) is the goldstandard approach in assessing CRF with an objective method and is probably the most comprehensive wholebody testing technique which allows the holistic evaluation of human body performance during exercise $[1,2]$. Although test indications limited for a long time to a narrowed study of certain pathophysiological conditions, CPET now has transformed to a valuable tool to daily clinical practice as a result of a growing awareness of the considerable amount of valuable information provided. Subsequently, indications for ventilatory expired gas analysis during exercise have broadened to a wide array of confirmed or suspected cardiopulmonary diseases as well as musculoskeletal conditions and finally to individuals without a medical diagnosis [3-9]. The aim of this review is to help Clinical Cardiologists to become familiar with CPET technique and its key measured variables, to refresh their knowledge regarding the underlying pathophysiological mechanisms of oxygen transport chain, and to learn how to interpret the most important CPET results. karger@karger.com www.karger.com/crd (c) 2021 S. Karger AG, Basel

Karger'"
Correspondence to:

Helen Triantafyllidi, seliani@ hotmail.com 


\section{Which Patient's Populations Take Advantage from a Cardiopulmonary Exercise Test?}

In cardiopulmonary disorders, the exercise intolerance is a major clinical feature from the early stages, becomes a source of symptoms and the predominant reason for referral to a physician. Its quantification may be approximated by several methods, but a thorough analysis of the organ systems and pathways involved in the impaired physiological response is obtained by exercise gas exchange analysis with CPET. The latter remains the gold-standard test for the selection of heart transplantation candidates with end-stage $\mathrm{HF}[7,10]$. Since exercise intolerance is one of the most disabling problems regarding patients with HF [7], the combined use of CPET-derived variables has led the physicians to the development of algorithms [11] and risk scores [12-14] covering the entire set of HF stages in patients with reduced or preserved left ventricular (LV) ejection fraction. Indeed, in patients with either HF or pulmonary arterial hypertension $(\mathrm{PAH})$, the change in exercise capacity parallels with other clinical indicators of disease severity, such as survival, hemodynamic parameters, and time to clinical worsening [15].

Besides patients with $\mathrm{HF}$, the role of routine CPET in Cardiology has been extended to other specific patient populations (unexplained dyspnoea [9], suspected ischemic heart disease [16], congenital heart or valvular diseases [17, 18], cardiomyopathies [19], suspected or confirmed PAH or even left-sided pulmonary hypertension [20-22]). Importantly, CPET has become a reproducible [23] and safe technique [24].

\section{The Significance of Cardiopulmonary Exercise Test in Athletes}

CPET is an important tool to optimize performance as part of a training program or for clinical purposes in athletes with established cardiovascular disease or in those with symptoms suggestive of cardiopulmonary pathology. Athletes demonstrate differences in exercise hemodynamic and gas exchange profiles as compared to nonathletes including higher cardiac output, faster heart rate recovery, higher peak $\mathrm{VO}_{2}$, higher prevalence of exerciseinduced arterial hypoxemia, and lower breathing reserve (BR). The impact of routine, vigorous physical activity on exercise physiology should be integrated into determination of what constitutes a normal CPET result in an athletic individual [25].

CPET ABC for the Cardiologist

\section{Using CPET for Diagnosis and Differentiation between Athletic Adaptation and Early Cardiomyopathy}

LV enlargement not associated with systolic dysfunction and outside the context of a familial disease in trained individuals generally represents a benign physiological adaptation, especially if it is consistent with the type of sports participated (usually, endurance sports) and the body size of the athlete. On the contrary, a mildly reduced EF (45-50\%) in an athlete with an enlarged LV cavity should not simply be considered as a normal adaptation. In these athletes, the presence of reduced peak oxygen consumption on CPET may provide supporting information for the differential diagnosis between athletic adaptation and early cardiomyopathy, especially in the context of an appropriate family history [26].

\section{The Significance of Cardiopulmonary Exercise Test regarding Exercise Prescription}

For medically stable individuals undergoing CPET, achieved volume of oxygen uptake $\left(\mathrm{VO}_{2}\right)$ at the level of the anaerobic threshold (AT) holds broad applicability in the context of assessing an individual's aerobic exercise capacity and determining the appropriate training intensity for a structured aerobic exercise program. Thus, the heart rate and workload that correspond to the level of an individual's $\mathrm{VO}_{2}$ at AT should be used as targets for an aerobic exercise training program [6]. It is expected that an individual will improve $\mathrm{VO}_{2}$ at $\mathrm{AT}$ (higher level) at the end of the training program.

\section{Using the Changes in Peak $\mathrm{VO}_{2}$ as a Clinical Trial Endpoint}

It seems that monitoring the changes in peak $\mathrm{VO}_{2}$ over time may be useful in HF patients. Indeed, a secondary analysis of the HF-ACTION study regarding the exercise training in $\mathrm{HF}$ patients indicated that a modest increase in peak $\mathrm{VO}_{2}$ over 3 months was associated with a lower composite rate of all-cause mortality and all-cause hospitalization, even in the setting of optimal medical and device therapy for chronic systolic HF [27]. However, the results of a recent meta-analysis indicated that improvements in exercise capacity, estimated by CPET or 6MWT, after exercise-based cardiac rehabilitation, was a poor 
surrogate endpoint for mortality and hospitalization in HF patients with a moderate validity for health-related quality of life [28].

\section{The Chain of Oxygen Delivery during Exercise}

Throughout CPET, the analysis of gas exchange during exercise is estimated. Modern systems measure breath by breath the $\mathrm{VO}_{2}$ and the volumes of carbon dioxide production $\left(\mathrm{VCO}_{2}\right)$ and air expired (Ventilation [VE]) [29]. The human body behaves under physical stress as an integrated system which delivers oxygen $\left(\mathrm{O}_{2}\right)$ to mitochondria in order to perform aerobic exercise [30]. Optimal $\mathrm{O}_{2}$ delivery depends on a set of biological interactions between the components of the $\mathrm{O}_{2}$ transport chain (lung alveolar diffusion, blood oxygenation, cardiac output [CO], $\mathrm{O}_{2}$-carrying capacity of the blood, oxygen delivery, and adequate release to working muscles). Subsequently, CPET may reveal alterations in multiple body functions including the cardiovascular, respiratory, muscular, sympathetic, and neuro-hormonal systems $[31,32]$.

\section{Estimation of $\mathrm{O}_{2}$ Consumption by the Fick Principle}

CPET enables the clinician to investigate potential causes of dyspnea and fatigue, precisely differentiate cardiac from pulmonary disorders, optimize the decisionmaking process and outcome prediction, and objectively determine targets for therapies [9]. These can be described by analyzing the framework of the Fick principle which estimates $\mathrm{VO}_{2}$ by the following equation: $\mathrm{VO}_{2}=$ stroke volume $(\mathrm{SV}) \times$ heart rate $\times\left(\mathrm{CaO}_{2}-\mathrm{CvO}_{2}\right)$, where $\mathrm{CaO}_{2}$ is arterial oxygen content, $\mathrm{CvO}_{2}$ is venous oxygen content and $\left(\mathrm{CaO}_{2}-\mathrm{CvO}_{2}\right)$ is the arteriovenous (a-v) difference in $\mathrm{O}_{2}$. Conclusively, $\mathrm{O}_{2}$ delivery depends on $\mathrm{SV}$ and heart rate $(\mathrm{CO})$ but also on the mechanisms involved in $\mathrm{O}_{2}$ dissociation from hemoglobin (the ability of $\mathrm{O}_{2}$ to diffuse from capillaries to cells and on mitochondria function). Gladly, tissue $\mathrm{O}_{2}$ extraction remains preserved due to an "optimized" peripheral blood flow redistribution and high mitochondrial activity even in the presence of an inadequate increase in CO [33-35].

Normal, healthy adults can increase $\mathrm{VO}_{2}$ up to 6-fold during exercise. The relative contribution of Fick's equation determinants to $\mathrm{VO}_{2}$ changes is approximately 1.2-, 2.5-, and 2.5-fold for SV, heart rate, and $\mathrm{CaO}_{2}-\mathrm{CvO}_{2}$, respectively [10].

\section{Choosing between Bike-Ergometer versus Treadmill for a Cardiopulmonary Exercise Test}

During CPET, the patient either rides a stationary bicycle (bike-ergometer) or walks on a treadmill while breathing through a nonrebreathing mask and wearing electrocardiographic leads, a blood pressure cuff, and a pulse oximeter. When using a bike-ergometer, subjects are submitted to a ramp exercise protocol which permits a true estimation of workload. The most important point in favor of a bike-ergometer is the linearity in workload change. Using a treadmill, it is possible to change slope and speed, but not the workload itself, so that it is almost impossible to generate a linear increase in workload [36]. On the other hand, exercise in a treadmill may more accurately reflect the patient's experience of exercise in dayto-day life compared to a bike-ergometer. A relevant issue in favor of the treadmill use is the potentially limited ability and habit of a number of the subjects to pedal. While biking is common in Europe and Eastern Asia, this is not the case in North and South America where, indeed, a treadmill is most frequently used. Finally, treadmill more readily highlights posture-dependent cardiac abnormalities like subaortic stenosis in LVOT obstruction and mitral insufficiency in mitral valve prolapse.

\section{Protocol Description of a Cardiopulmonary Exercise Test}

The test starts out easy and gets progressively harder until the patient fatigues, reaches $\geq 90 \%$ of his/her predicted maximum heart rate (maximum heart rate [beats per $\min ]=220$-age [years]) or, as in any stress test, experiences any other clinical indication for stopping, such as arrhythmias, hypotension, or severe symptoms (dyspnoea, angina, pre-syncope). Although CPET resembles exercise stress test, its purpose is not the ischemia or arrhythmia diagnostic evaluation. Instead, CPET estimates an individual's fair or poor physical condition and is based on circulatory, metabolic, and ventilatory parameters. Patients are advised to wear comfortable workout clothes, and asked to try as hard as they can. The selected exercise ramp protocol, must allow exercise duration of $\sim 10$ min with an accepted interval ranging from 8 to 12 min $[37,38]$. This means that the workload increase should be personalized for each patient, in order to achieve this test duration. Data must be recorded breath by breath. For interpretation, data are usually averaged by fixed time intervals (usually 20-30 s). Prediction equa- 


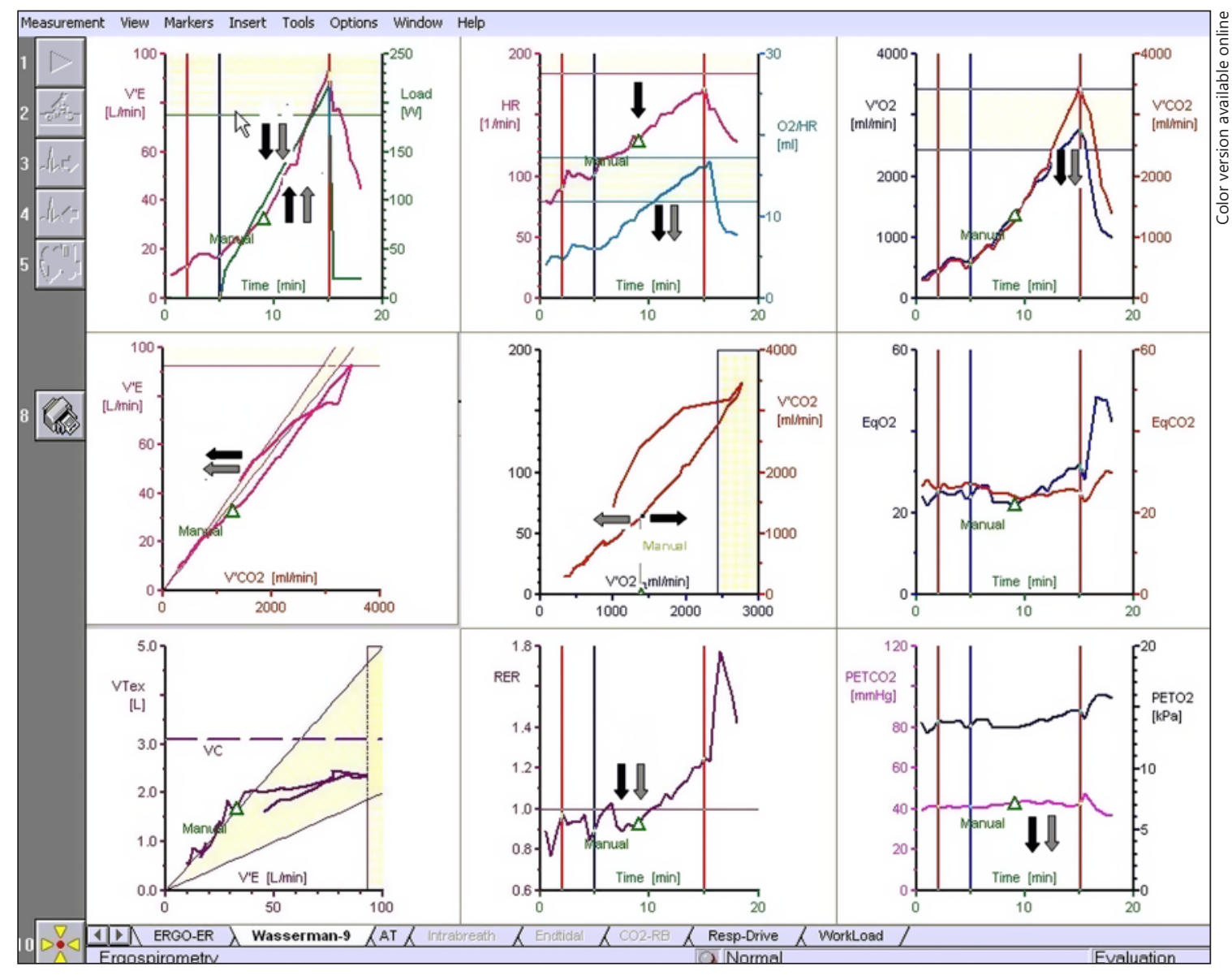

Fig. 1. The Wassermann's 9-plot after a CPET session of a normal subject. Grey (cardiac) and black (respiratory) arrows show the expected differences in several variables: VE (both increase), Load (both decrease), HR (decrease in respiratory disease), $\mathrm{O}_{2}$ pulse (both decrease), peak $\mathrm{VO}_{2}$ (both decrease), $\mathrm{AT}$ (decrease in heart disease), $\mathrm{RER}$ (both decrease), $\mathrm{PETCO}_{2}$ (both decrease), and $\mathrm{VE} / \mathrm{VCO}_{2}$ slope (both increase) derived from cardiac and respiratory deficiencies, respectively. Manual indicates AT.

tions are needed to allow comparison of subjects of different gender, ethnicity, age, height, and weight [39]. It is well known that in overweight and underweight subjects, normalization for weight is mandatory [36]. Patients are instructed to take all of their usual medications, including $\beta$-blockers, unless advised otherwise at the discretion of the supervising physician [29]. It is important to keep in mind that patients with HF who do not reach their predicted maximal heart rate (due to medications) may have given a maximal effort. In a situation like this, the respiratory exchange ratio (RER), calculated as the ratio between $\mathrm{VCO}_{2}$ and $\mathrm{VO}_{2}$, is important as an indicator whether a maximal or near maximal exercise test has been performed. Indeed, RER $>1.05$ or even better $>1.10$ indicates a good effort [36].

\section{Cardiopulmonary Exercise Test Protocols}

There are several protocols that can be used with either a cycle ergometer or a treadmill. Classification is based on the manner in which the work rate is applied: (1) a progressive incremental exercise protocol (every minute) or a continuous ramp exercise protocol (every 1-2 $\mathrm{s}$ in a ramp-like fashion). Those almost equal protocols are usually applied in a cycle ergometer (commonly used in clinical practice); (2) a multistage exercise protocol applied in a treadmill, i.e., Bruce or Naughton protocols (every $3 \mathrm{~min}$, with a steady state at each level); (3) a constant work rate applied in either a treadmill or a cycle ergometer (the same work rate, usually for 5-30 min); or (4) a discontinuous protocol, which consists of short periods 
Table 1. Key variables during a CPET session and their normal values at peak exercise

\begin{tabular}{|c|c|}
\hline Parameter & $\begin{array}{l}\text { Expected values at } \\
\text { peak exercise }\end{array}$ \\
\hline \multicolumn{2}{|l|}{ Exercise } \\
\hline Duration, min & $8-12$ \\
\hline Work load, \% predicted & $>80$ \\
\hline RER & $>1.15$ \\
\hline \multicolumn{2}{|l|}{ Hemodynamic } \\
\hline Systolic blood pressure, $\mathrm{mm} \mathrm{Hg}$ & $<220$ \\
\hline Heart rate, $\%$ predicted & $>90$ \\
\hline Heart rate reserve, $\%$ predicted & $<10$ \\
\hline Heart rate recovery (beats at $1^{\circ}$ recovery) & $>12$ \\
\hline \multicolumn{2}{|l|}{ Metabolic } \\
\hline Peak $\mathrm{VO}_{2}, \%$ predicted & $>84$ \\
\hline $\mathrm{AT}, \%$ predicted $\mathrm{VO}_{2}$ & $>40$ \\
\hline $\mathrm{O}_{2}$ pulse, $\%$ & $>80$ \\
\hline $\mathrm{VO}_{2} /$ work, $\mathrm{mL} / \mathrm{min} / \mathrm{W}$ & $9-11$ \\
\hline \multicolumn{2}{|l|}{ Ventilatory } \\
\hline $\mathrm{BF}$, breaths/min & $<60$ \\
\hline $\mathrm{BR}, \%$ & $>20-40$ \\
\hline $\mathrm{PETCO}_{2}$ at baseline, $\mathrm{mm} \mathrm{Hg}$ & $>33$ \\
\hline $\mathrm{PETCO}_{2}$ at $\mathrm{AT}, \mathrm{mm} \mathrm{Hg}$ compared to baseline & $>3-6$ \\
\hline $\mathrm{O}_{2}$ desaturation, $\%$ & $<4$ \\
\hline \multicolumn{2}{|l|}{ Prognostic } \\
\hline VE/ $/ \mathrm{VCO}_{2}$ slope & $<34$ \\
\hline $\mathrm{O}_{2}$ recovery slope & $>650$ \\
\hline
\end{tabular}

$\mathrm{BF}$, breathing frequency.

(3-4 min) of constant work rate exercise separated by resting periods and with loads progressively increased (rarely used clinically) $[3,40]$.

\section{Key Variables Derived from a Cardiopulmonary Exercise Test}

Overall, despite a wealth of persuasive evidence and numerous statements supporting the utility of CPET in prevention and in early stages of several cardiopulmonary diseases, practitioners have not generally adopted a portfolio of variables that provides a 3-dimensional view of cardiorespiratory fitness with diagnostic and prognostic applicability, and an effective means to evaluate therapeutic benefits [10]. CPET variables (independently and combined) offer useful prognostic information. The Wassermann's 9-plot uses several CPET variables as they interact to each other. Many of them reflect the ventilator, cardiac and metabolic inefficiencies that result from the extensive central and peripheral pathophysiological mechanisms seen in patients with cardiopulmonary diseases (shown in Fig. 1) [41-43]. Besides the metabolic variables, the ventilatory ones are important even in patients with HF who usually present a lung restrictive syndrome due to congestion and physical interaction between the heart and lung [44-46] with impaired exerciseinduced tidal volume increase [47-50] and an expiratory flow limitation $[46,51]$. The following main parameters are examined and interpreted at the end of the test, usually by the order they appear below, in order to evaluate the adequacy of the examinee's effort (Table 1).

\section{Respiratory Exchange Ratio}

It is calculated as the ratio between peak $\mathrm{VCO}_{2}$ production and peak $\mathrm{VO}_{2}$ consumption, is important as an indicator whether a maximal or near maximal exercise test has been performed. Exceeding a RER value of 1.05 and even better 1.15 indicates a good effort [52].

\section{Workload}

It represents the maximum load to which the examinee is subjected during CPET session in order to produce work. It is referred as an absolute value (in watts) as well as in relation to its predicted value (\%). Maximum workload $>90 \%$ predicted is necessary in order to indicate a good effort [53].

\section{Max Heart Rate}

The examinee has to reach $\geq 90 \%$ of his/her predicted maximum heart rate in order to complete a maximal exercise. Although patients under chronotropic medications are not sometimes capable to meet this criterion, a maximal exercise maybe completed as it is indicated by the interpretation of RER and Workload [36].

\section{$\mathrm{VO}_{2}$ at Peak Exercise $\left(\right.$ Peak $\left.\mathrm{VO}_{2}\right)$}

It is the most important parameter derived from a CPET and at the same time is the gold standard to objectively assess functional limitations in cardiac patients [7]. It can be reported as $\mathrm{VO}_{2}$ max or peak $\mathrm{VO}_{2}$. Peak $\mathrm{VO}_{2}$ describes the highest achieved $\mathrm{VO}_{2}$ value during an exercise test (averaged over a complete $20-30$ s period). Peak $\mathrm{VO}_{2}$ can be reported as an absolute value $(\mathrm{mL} / \mathrm{min})$ or indexed by body weight $(\mathrm{mL} / \mathrm{min} / \mathrm{kg})$ or as a percentage of predicted value (\%) normalized to sex, age, height, and weight measurement. Weber's classification characterizes the individual's response to exercise as normal when $\mathrm{VO}_{2}>20 \mathrm{~mL} / \mathrm{min} / \mathrm{kg}$ (stage A), mildly to moderately im- 
paired when $\mathrm{VO}_{2} \leq 20 \mathrm{~mL} / \mathrm{min} / \mathrm{kg}$ (stage $\mathrm{B}$ ), moderately to severely impaired when $\mathrm{VO}_{2} \leq 16 \mathrm{~mL} / \mathrm{min} / \mathrm{kg}$ (stage C) and severely impaired when $\mathrm{VO}_{2} \leq 10 \mathrm{~mL} / \mathrm{min} / \mathrm{kg}$ (stage $\mathrm{D})$. It is important to consider that the absolute peak $\mathrm{VO}_{2}$ value is $\sim 10 \%$ higher on a treadmill, compared to a cycle ergometer [54].

To this day, a peak $\mathrm{VO}_{2}$ equal or above $14 \mathrm{~mL} / \mathrm{kg} / \mathrm{min}$ remains a positive prognostic threshold with lower values carrying a poor CV prognosis [3]. Moreover, heart transplant guidelines report that $\mathrm{HF}$ patients with peak $\mathrm{VO}_{2}$ threshold values $\geq 12 \mathrm{~mL} / \mathrm{min} / \mathrm{kg}$ or $\geq 14 \mathrm{~mL} / \mathrm{min} / \mathrm{kg}$ (in those treated or not treated by $\beta$-blockers, respectively) may be safely removed from the transplantation list [55, 56]. However, both the absolute and the $\%$ of predicted peak $\mathrm{VO}_{2}$ value must be reported and combined since the latter seems more reliable than absolute values in patients with HF $[7,57,58]$. In the recent ESC position paper regarding the role of CPET in clinical stratification in heart failure, the achievement of a peak $\mathrm{VO}_{2} \geq 18 \mathrm{~mL} / \mathrm{min} / \mathrm{kg}$ from patients with HFrEF confers a favorable outcome [53]. However, this might not be fit for "specific" individual patients as the very young patients with HFrEF. In this group, a peak $\mathrm{VO}_{2}$ equal to $18 \mathrm{~mL} / \mathrm{kg} / \mathrm{min}$ might already be significantly reduced, and the integration of peak $\mathrm{VO}_{2}$ percentage might be useful [53].

\section{$\mathrm{VE} / \mathrm{VCO}_{2}$ Slope}

$\mathrm{VE} / \mathrm{VCO}_{2}$ responses to exercise typically evaluate ventilatory efficiency providing information about the effectiveness of the minute $\mathrm{VE}$ for a given metabolic rate. When $\mathrm{VE} / \mathrm{VCO}_{2}$ is elevated, it is important to understand the underlying physiological mechanism for the increased VE relative to metabolic rate (increase in dead space and/ or alveolar VE) [59]. $\mathrm{VE} / \mathrm{VCO}_{2}$ is undoubtedly, the most relevant ventilatory parameter, which has a key prognostic role in HF, pulmonary artery hypertension, congenital heart disease, and lung diseases (normal values $<34$ ) either as a single value or in combination with other parameters [60]. Therapeutic intervention in cardiovascular and lung diseases aims to improve prognosis, limit morbidity, and increase the quality of life, all of which are markers associated with higher peak $\mathrm{VO}_{2}$ values and lower VE/ $/ \mathrm{VCO}_{2}$ slopes [10].

\section{AT or Otherwise Ventilatory Threshold}

Achieved either earlier than expected or on time, AT is important in order to evaluate an individual's aerobic capacity to exercise. It is defined as the $\mathrm{VO}_{2}$ at the time point of the anaerobic metabolism initiation (submaximal exercise) which can be determined using the expired concentrations of oxygen and carbon dioxide during a CPET session. Researchers have also used the terms " 1 st and 2nd AT" (also termed the "AT" and "point of respiratory compensation," respectively) to establish the exercise intensity. Given that metabolic acidosis drives pulmonary VE, an inflection in blood lactate concentration above baseline levels is coincident to the 1st AT while at 2nd AT, a higher marker of exercise intensity compared to 1st AT, lactate has quickly accumulated in the blood [61].

There are 3 CPET-derived methods for detecting $\mathrm{VO}_{2}$ at AT: (i) the $\mathrm{V}$-slope, the point at which the incremental volume of $\mathrm{VCO}_{2}$ becomes higher, as compared with $\mathrm{VO}_{2}$, due to the additional $\mathrm{CO}_{2}$ produced by lactic acid buffering; (ii) the end-tidal $\mathrm{CO}_{2}\left(\mathrm{PETCO}_{2}\right)$ versus the end-tidal $\mathrm{O}_{2}\left(\mathrm{PETO}_{2}\right)$ method (when an opposite kinetic point of these variables occurs with $\mathrm{PETO}_{2}$ progressively increasing and the $\mathrm{PETCO}_{2}$ slightly decreasing); and (iii) the oxygen minute $\mathrm{VE}$ equivalent $\left(\mathrm{VE} / \mathrm{VO}_{2}\right)$ versus carbon dioxide minute $\mathrm{VE}$ equivalent $\left(\mathrm{VE} / \mathrm{VCO}_{2}\right)$ change in pattern (the point of continuous increase in $\mathrm{VE} / \mathrm{VO}_{2}$ and stable $\mathrm{VE} / \mathrm{VCO}_{2}$ kinetics) [10]. Ventilatory equivalents $\left(\mathrm{VE} / \mathrm{VO}_{2}, \mathrm{VE} / \mathrm{VCO}_{2}\right)$ and end-tidal partial pressures $\left(\mathrm{PETO}_{2}, \mathrm{PETCO}_{2}\right)$ represent the ventilatory response of anaerobic metabolism generated at the muscular level [62]. Inability to determine the AT with any of these methods occurs approximately in $10 \%$ of patients with $\mathrm{HF}$ and carries a strong independent prognostic role [10].

\section{Oxygen Pulse}

It is the ratio of $\mathrm{VO}_{2}$ to heart rate and reflects the amount of $\mathrm{O}_{2}$ extracted per heartbeat. The $\mathrm{O}_{2}$ pulse provides an estimate of LV SV changes during exercise, assuming that (a-v) $\mathrm{O}_{2}$ is maximal and no anemia or hypoxia is present [10]. A low, unchanging flat $\mathrm{O}_{2}$ pulse with increasing work rate be interpreted as resulting from a reduced SV and/or as a failure for further skeletal muscle $\mathrm{O}_{2}$ extraction [3]. In a recent study, abnormal $\mathrm{O}_{2}$ pulse curve pattern had low sensitivity and negative predictive value for the diagnosis of obstructive CAD since it was not associated with the myocardial ischemia defined by scintigraphy. Instead, a flat $\mathrm{O}_{2}$ pulse curve was associated with the extent of global perfusion defect, probably reflecting myocardial dysfunction [63].

\section{$\mathrm{VO}_{2} /$ Work Load Ratio}

Observed during the entire exercise, it attracts pathophysiological interest since it shows oxygen delivery to the working muscles. It increases throughout the entire 


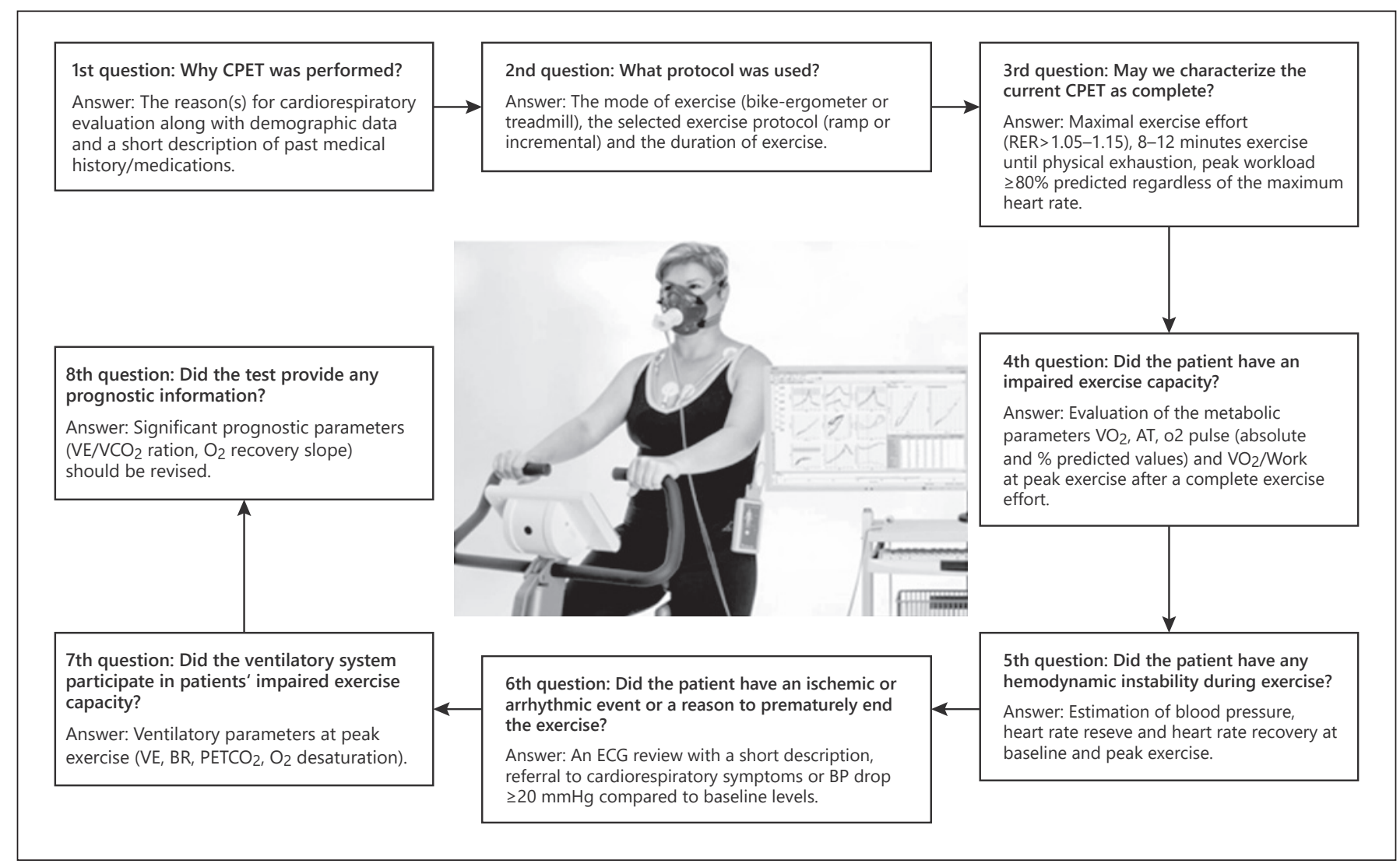

Fig. 2. How to interpret a CPET and fill the report form.

incremental exercise period in parallel with the aerobic ATP augmentation reaching normal values $(9-11 \mathrm{~mL} /$ $\mathrm{min} / \mathrm{W}$ ). Reduced values of the $\mathrm{VO}_{2}$ versus work relationship imply an impaired $\mathrm{O}_{2}$ delivery [3]. Moreover, this slope can be suddenly decreased during exercise, due to cardiac ischemia or mitral insufficiency [64].

\section{$\mathrm{PETCO}_{2}$ Kinetics}

When estimated at baseline, AT and peak exercise it will help discrimination between a normal performed exercise or an exercise under the patterns of HF or chronic obstructive pulmonary disease (COPD) or PAH [65]. Normally, $\mathrm{PETCO}_{2}$ is $>33 \mathrm{~mm} \mathrm{Hg}$ at baseline, increases by $>3-6 \mathrm{~mm} \mathrm{Hg}$ at the AT point and then decreases at peak exercise just above the baseline values. In HF and COPD, $\mathrm{PETCO}_{2}$ is $<33 \mathrm{~mm} \mathrm{Hg}$ at baseline and increases less than $3 \mathrm{~mm} \mathrm{Hg}$ at the AT point. However, $\mathrm{PETCO}_{2}$ decreases at peak exercise in $\mathrm{HF}$ while it forms a plateau in COPD. Finally, in PAH $\mathrm{PETCO}_{2}$ starts well $<33 \mathrm{~mm}$ $\mathrm{Hg}$ at baseline and continuously decreases at the AT point and the peak exercise [59].

\section{Breathing Reserve}

It describes the relationship between exercise VE and maximal breathing capacity, as estimated by resting maximal voluntary VE [3]. Values $<15 \%$ suggest a ventilatory limitation and may help to discriminate between patients with HF and those with comorbid COPD [66].

\section{Differential Diagnosis between the Circulatory or Respiratory System Insufficiency and Poor Physical Condition}

When a subject/patient achieves a lower than expected peak $\mathrm{VO}_{2}$ after a CPET session, we need to differentiate between the circulatory/respiratory system insufficiency and poor physical condition. Circulatory system insufficiency is characterized by exhaustion, max HR max HR predicted, RER $\geq 1.1, \mathrm{O}_{2}$ saturation $>88 \%$, no ventilatory limitation. On the other hand, respiratory system insufficiency is characterized by exhaustion, $\max$ $\mathrm{HR}<\max \mathrm{HR}$ predicted, $\mathrm{AT}>40 \% \max \mathrm{VO}_{2}$ predicted, 
$\mathrm{O}_{2}$ saturation $<88 \%$, and ventilatory limitation (BR $<15 \%$, expiratory flow limitation, and hyperinflation). Finally, in poor physical condition, $\mathrm{VO}_{2}$ at $\mathrm{AT}$ is moderately decreased (<40\% max $\mathrm{VO}_{2}$ predicted), max $\mathrm{HR} \sim$ max $\mathrm{HR}$ predicted, $\mathrm{BR}>15 \%$ and $\% \mathrm{O}_{2}$ saturation $>88 \%$ [59].

\section{How to Interpret a Cardiopulmonary Exercise Test and Fill the Report Form}

A 8-step approach consisted of 8 questions and their corresponding answers will be valuable in order for the clinician to fill the CPET report form. The latter including data from all exercise phases (baseline, AT, peak exercise, and recovery) will give answers to the following questions regarding the evaluation of a subject's/patient's ability for exercise. A clear interpretation of the findings should be provided in order to facilitate the appropriate diagnostic or/and therapeutic decisions (shown in Fig. 2).

\section{1st Question: Why CPET Was Performed?}

The reason(s) for the examinee's (or patient's) referral to a CPET laboratory regarding his cardiorespiratory evaluation (dyspnea, easy fatigue, evaluation of cardiopulmonary disease severity, and/or treatment plan sufficiency) along with his demographics (gender, age, height, and weight) and a short description of past medical history/medications need to be included in the CPET report form.

\section{2nd Question: What Protocol Was Used?}

The mode of exercise (bike-ergometer or treadmill), the selected exercise protocol (ramp or incremental) and the duration of exercise answer that question.

\section{3rd Question: May We Characterize the Current}

CPET as Complete?

If the examinee/patient achieved a maximal exercise effort (RER $>1.05-1.15$ ) while exercised for 8-12 min until physical exhaustion reaching peak work load $>80 \%$ predicted and regardless of the maximum heart rate, then the current CPET session should be characterized as complete.

\section{4th Question: Did the Patient Have an Impaired}

Exercise Capacity?

The evaluation of the metabolic parameters $\mathrm{VO}_{2}$, AT, $\mathrm{O}_{2}$ pulse (presented as absolute and \% predicted values) and $\mathrm{VO}_{2}$ /work at peak exercise after a complete exercise effort characterize the examinee's (or patient's) exercise capacity as adequate or abnormal.

\section{5th Question: Did the Patient Have Any}

Hemodynamic Instability During Exercise?

The estimation of hemodynamic parameters at baseline and peak exercise (blood pressure, heart rate, heart rate reserve, and heart rate recovery) evaluates any hemodynamic instability during exercise.

6th Question: Did the Patient Have an Ischemic or Arrhythmic Event or a Reason to Prematurely End the Exercise?

An ECG review during the whole exercise along with a short description should be provided in order to reveal any ischemic or arrhythmic events. Simultaneously, the presence of any cardiorespiratory symptoms or BP drop $\geq 20 \mathrm{~mm} \mathrm{Hg}$ compared to baseline levels (main reasons for exercise interruption) should be mentioned in CPET report form.

\section{7th Question: Did the Ventilatory System Participate}

in Patients' Impaired Exercise Capacity?

The study of ventilatory parameters at peak exercise (VE, BR, $\mathrm{PETCO}_{2}, \mathrm{O}_{2}$ desaturation) will give the appropriate answers. CPET may distinguish between circulatory and respiratory failure as well as poor physical condition responsible for impaired exercise capacity.

\section{8th Question: Did the Test Provide Any Prognostic} Information?

Significant prognostic parameters $\left(\mathrm{VE} / \mathrm{VCO}_{2}\right.$ ratio, $\mathrm{O}_{2}$ recovery slope) should be revised and mentioned in CPET report form.

\section{Conclusions}

CPET is the most comprehensive technique which allows an holistic approach to cardiopulmonary diseases. Clinical application of CPET continues to evolve and protocols should be adapted to each specific patient to obtain the most reliable and useful information. Interested Clinical Cardiologists should increase personal familiarity with test interpretation and promote appropriate patient referrals. 


\section{Conflict of Interest Statement}

The authors have no conflicts of interest to declare.

\section{Funding Sources}

This research received no specific grant from any funding sources.

\section{Author Contributions}

Conception of the work from H.T. and E.K.I., article draft created from H.T., critical revision of the article by D.B., D.B., P.T., and A.F., and final approval of the version to be published by H.T. and E.K.I.

\section{References}

1 Ross R, Blair SN, Arena R, Church TS, Després JP, Franklin BA, et al. Importance of assessing cardiorespiratory fitness in clinical practice: a case for fitness as a clinical vital sign: a scientific statement from the American Heart Association. Circulation. 2016;134:e653-99.

2 Mezzani A. Cardiopulmonary exercise testing: basics of methodology and measurements. Ann Am Thorac Soc. 2017;14(Suppl 1):S3-11.

3 American Thoracic Society; American College of Chest Physicians. ATS/ACCP statement on cardiopulmonary exercise testing. Am J Respir Crit Care Med. 2003;167:211-77.

4 Lauer M, Froelicher ES, Williams M, Kligfield P. Exercise testing in asymptomatic adults: a statement for professionals from the American Heart Association Council on Clinical Cardiology, Subcommittee on Exercise, Cardiac Rehabilitation, and Prevention. Circulation. 2005;112:771-6.

5 Mezzani A, Agostoni P, Cohen-Solal A, Corrà U, Jegier A, Kouidi E, et al. Standards for the use of cardiopulmonary exercise testing for the functional evaluation of cardiac patients: a report from the Exercise Physiology Section of the European Association for Cardiovascular Prevention and Rehabilitation. Eur J Cardiovasc Prev Rehabil. 2009;16:249-67.

6 Balady GJ, Arena R, Sietsema K, Myers J, Coke L, Fletcher GF, et al. Clinician's guide to cardiopulmonary exercise testing in adults: a scientific statement from the American Heart Association. Circulation. 2010;122:191-225.

7 Guazzi M, Adams V, Conraads V, Halle M, Mezzani A, Vanhees L, et al. EACPR/AHA scientific statement: clinical recommendations for cardiopulmonary exercise testing data assessment in specific patient populations. Circulation. 2012;126:2261-74.

8 Kaminsky L, Arena R, Myers J. Reference standards for cardiorespiratory fitness measured with cardiopulmonary exercise testing: data from the fitness registry and the importance of exercise national database. Mayo Clin Proc. 2015;90:1511-23.

9 Guazzi M, Arena R, Halle M, Piepoli MF, Myers J, Lavie CJ. 2016 focused update: clinical recommendations for cardiopulmonary exercise testing data assessment in specific patient populations. Circulation. 2016;133(24):e694711.
10 Guazzi M, Bandera F, Ozemek C, Systrom D, Arena R. Cardiopulmonary exercise testing: what is its value? J Am Coll Cardiol. 2017; 70(13):1618-36.

11 Lim HS, Theodosiou M. Exercise ventilatory parameters for the diagnosis of reactive pulmonary hypertension in patients with heart failure. J Card Fail. 2014;20:650-7.

12 Agostoni P, Corrà U, Cattadori G, Veglia F, La Gioia R, Scardovi AB, et al. Metabolic exercise test data combined with cardiac and kidney indexes, the MECKI score: a multiparametric approach to heart failure prognosis. Int J Cardiol. 2013;167:2710-8.

13 Levy WC, Aaronson KD, Dardas TF, Williams P, Haythe J, Mancini D. Prognostic impact of the addition of peak oxygen consumption to the Seattle heart failure model in a transplant referral population. J Heart Lung Transplant. 2012;31:817-24.

14 Lund LH, Aaronson KD, Mancini DM. Validation of peak exercise oxygen consumption and the heart failure survival score for serial risk stratification in advanced heart failure. Am J Cardiol. 2005;95:734-41.

15 Oudiz RJ. Role of exercise testing in PAH management. Semin Respir Crit Care Med. 2005;26(4):379-84.

16 Chaudhry S, Kumar N, Behbahani H, Bagai A, Singh BK, Menasco N, et al. Abnormal heartrate response during cardiopulmonary exercise testing identifies cardiac dysfunction in symptomatic patients with non-obstructive coronary artery disease. Int J Cardiol. 2017; 228:114-21.

17 Barber NJ, Ako EO, Kowalik GT, Cheang MH, Pandya B, Steeden JA, et al. Magnetic resonance-augmented cardiopulmonary exercise testing: comprehensively assessing exercise intolerance in children with cardiovascular disease. Circ Cardiovasc Imaging. 2016; 9(12):e005282.

18 Bandera F, Generati G, Pellegrino M, Garatti A, Labate V, Alfonzetti E, et al. Mitral regurgitation in heart failure: insights from CPET combined with exercise echocardiography. Eur Heart J Cardiovasc Imaging. 2017;18:296-303.

19 Coats CJ, Rantell K, Bartnik A, Patel A, Mist B, McKenna WJ, et al. Cardiopulmonary exercise testing and prognosis in hypertrophic cardiomyopathy. Circ Heart Fail. 2015;8: 1022-31.
20 Triantafyllidi H, Kontsas K, Trivilou P, Orfanos SE, Lekakis J, Kremastinos D, et al. The importance of cardiopulmonary exercise testing in the diagnosis, prognosis and monitoring of patients with pulmonary arterial hypertension. Hellenic J Cardiol. 2010;51(3):245-9.

21 Charalampopoulos A, Gibbs JS, Davies RJ, Gin-Sing W, Murphy K, Sheares KK, et al. Exercise physiological responses to drug treatments in chronic thromboembolic pulmonary hypertension. J Appl Physiol (1985). 2016;121:623-8.

22 Guazzi M, Cahalin LP, Arena R. Cardiopulmonary exercise testing as a diagnostic tool for the detection of left-sided pulmonary hypertension in heart failure. J Card Fail. 2013; 19:461-7.

23 Barron A, Dhutia N, Mayet J, Hughes AD, Francis DP, Wensel R. Test-retest repeatability of cardiopulmonary exercise test variables in patients with cardiac or respiratory disease. Eur J Prev Cardiol. 2014;21:445-53.

24 Skalski J, Allison TG, Miller TD. The safety of cardiopulmonary exercise testing in a population with high-risk cardiovascular diseases. Circulation. 2012;126:2465-72.

25 Petek BJ, Gustus SK, Wasfy MM. Cardiopulmonary exercise testing in athletes: expect the unexpected. Curr Treat Options Cardio Med. 2021;23(7).

26 Pelliccia A, Sharma S, Gati S, Bäck M, Börjesson M, Caselli S, et al. 2020 ESC guidelines on sports cardiology and exercise in patients with cardiovascular disease. Eur Heart J. 2021 Jan 1;42(1):17-96.

27 Ciani O, Piepoli M, Smart N, Uddin J, Walker $\mathrm{S}$, Warren FC, et al. Validation of exercise capacity as a surrogate endpoint in exercisebased rehabilitation for heart failure: a metaanalysis of randomized controlled trials. JACC Heart Fail. 2018;6(7):596-604.

28 Swank AM, Horton J, Fleg JL, Fonarow GC, Keteyian S, Goldberg L, et al. Modest increase in peak VO2 is related to better clinical outcomes in chronic heart failure patients: results from heart failure and a controlled trial to investigate outcomes of exercise training. Circ Heart Fail. 2012;5(5):579-85.

29 Leclerc K. Cardiopulmonary exercise testing: a contemporary and versatile clinical tool. Cleve Clin J Med. 2017;84(2):161-8. 
30 Wasserman K. Coupling of external to cellular respiration during exercise: the wisdom of the body revisited. Am J Physiol. 1994;266: E519-39.

31 Ponikowski P, Voors AA, Anker SD, Bueno H, Cleland JGF, Coats AJS, et al. 2016 ESC Guidelines for the diagnosis and treatment of acute and chronic heart failure: the Task Force for the diagnosis and treatment of acute and chronic heart failure of the European Society of Cardiology (ESC) developed with the special contribution of the Heart Failure Association (HFA) of the ESC. Eur Heart J. 2016, 37:2129-200.

32 Sato T, Yoshihisa A, Kanno Y, Suzuki S, Yamaki T, Sugimoto K, et al. Cardiopulmonary exercise testing as prognostic indicators: comparisons among heart failure patients with reduced, mid-range and preserved ejection fraction. Eur J Prev Cardiol. 2017;24: 1979-87.

33 Agostoni P, Wasserman K, Perego GB, Marenzi GC, Guazzi M, Assanelli E, et al. Oxygen transport to muscle during exercise in chronic congestive heart failure secondary to idiopathic dilated cardiomyopathy. Am J Cardiol. 1997;79:1120-4.

34 Esposito F, Mathieu-Costello O, Shabetai R, Wagner PD, Richardson RS. Limited maximal exercise capacity in patients with chronic heart failure: partitioning the contributors. J Am Coll Cardiol. 2010;55:1945-54.

35 Stringer WW, Hansen JE, Wasserman K. Cardiac output estimated noninvasively from oxygen uptake during exercise. J Appl Physiol (1985). 1997;82:908-12.

36 Agostoni P, Dumitrescu D. How to perform and report a cardiopulmonary exercise test in patients with chronic heart failure. Int J Cardiol. 2019;288:107-13.

37 Agostoni P, Bianchi M, Moraschi A, Palermo P, Cattadori G, La Gioia R, et al. Work-rate affects cardiopulmonary exercise test results in heart failure. Eur J Heart Fail. 2005;7:498504.

38 Buchfuhrer MJ, Hansen JE, Robinson TE, Sue DY, Wasserman K, Whipp BJ. Optimizing the exercise protocol for cardiopulmonary assessment. J Appl Physiol Respir Environ Exerc Physiol. 1983;55:1558-64.

39 Triantafyllidi H, Benas D, Birba D, Trivilou P, Iliodromitis E. Reference values for aerobic capacity estimated by cardiopulmonary exercise test on a cycle ergometer in a healthy Greek population. Hellenic J Cardiol. 2021 Mar-Apr;62(2):121-6.

40 Andersen KL, Shepard RJ, Denolin H, Varnauskas E, Masironi R. Fundamentals of exercise testing. Geneva, Switzerland: World Health Organization; 1971. Vol. 138.

41 Ponikowski P, Francis DP, Piepoli MF, Davies LC, Chua TP, Davos CH, et al. Enhanced ventilator response to exercise in patients with chronic heart failure and preserved exercise tolerance. Marker of abnormal cardiorespiratory reflex control and predictor of poor prognosis. Circulation. 2001;103:967-72.
42 Levy WC, Maichel BA, Steele NP, Leclerc KM, Stratton JR. Biomechanical efficiency is decreased in heart failure during low-level steady state and maximal ramp exercise. Eur J Heart Fail. 2004;6:917-26.

43 Poole DC, Hirai DM, Copp SW, Musch TI. Muscle oxygen transport and utilization in heart failure: implications for exercise (in)tolerance. Am J Physiol Heart Circ Physiol. 2012;302:H1050-63.

44 Wasserman K, Zhang YY, Gitt A, Belardinelli R, Koike A, Lubarsky L, et al. Lung function and exercise gas exchange in chronic heart failure. Circulation. 1997;96:2221-7.

45 Agostoni P, Bussotti M, Cattadori G, Margutti E, Contini M, Muratori M, et al. Gas diffusion and alveolar-capillary unit in chronic heart failure. Eur Heart J. 2006;27: 2538-43.

46 Agostoni P, Pellegrino R, Conca C, Rodarte JR, Brusasco V. Exercise hyperpnea in chronic heart failure: relationships to lung stiffness and expiratory flow limitation. J Appl Physiol (1985). 2002;92:1409-16.

47 Puri S, Baker BL, Dutka DP, Oakley CM, Hughes JM, Cleland JG. Reduced alveolarcapillary membrane diffusing capacity in chronic heart failure. Its pathophysiological relevance and relationship to exercise performance. Circulation. 1995;91:2769-74.

48 Puri S, Dutka DP, Baker BL, Hughes JM, Cleland JG. Acute saline infusion reduces alveolar-capillary membrane conductance and increases airflow obstruction in patients with left ventricular dysfunction. Circulation. 1999;99:1190-6.

49 Agostoni PG, Marenzi GC, Pepi M, Doria E, Salvioni A, Perego G, et al. Isolated ultrafiltration in moderate congestive heart failure. J Am Coll Cardiol. 1993;21:424-31.

50 Agostoni PG, Guazzi M, Bussotti M, Grazi M, Palermo P, Marenzi G. Lack of improvement of lung diffusing capacity following fluid withdrawal by ultrafiltration in chronic heart failure. J Am Coll Cardiol. 2000;36:1600-4.

51 Johnson BD, Beck KC, Olson LJ, O’Malley KA, Allison TG, Squires RW, et al. Ventilatory constraints during exercise in patients with chronic heart failure. Chest. 2000;117: 321-32.

52 Mezzani A, Corrà U, Bosimini E, Giordano A, Giannuzzi P. Contribution of peak respiratory exchange ratio to peak $\mathrm{VO} 2$ prognostic reliability in patients with chronic heart failure and severely reduced exercise capacity. Am Heart J. 2003;145:1102-7.

53 Corrà U, Agostoni PG, Anker SD, Coats AJS, Crespo Leiro MG, de Boer RA, et al. Role of cardiopulmonary exercise testing in clinical stratification in heart failure. A position paper from the Committee on Exercise Physiology and Training of the Heart Failure Association of the European Society of Cardiology. Eur J Heart Fail. 2018;20(1):3-15.

54 Wagner J, Agostoni P, Arena R, Belardinelli R, Dumitrescu D, Hager A, et al. The role of gas exchange variables in cardiopulmonary exercise testing for risk stratification and management of heart failure with reduced ejection fraction. Am Heart J. 2018;202:11626.

55 O’Neill JO, Young JB, Pothier CE, Lauer MS. Peak oxygen consumption as a predictor of death in patients with heart failure receiving beta-blockers. Circulation. 2005; 111:23138.

56 Cattadori G, Agostoni P, Corra U, Di Lenarda A, Sinagra G, Veglia F, et al. Severe heart failure prognosis evaluation for transplant selection in the era of beta blockers: role of peak oxygen consumption. Int J Cardiol. 2013;168: 5078-81.

57 Stelken AM, Younis LT, Jennison SH, Miller DD, Miller LW, Shaw LJ, et al. Prognostic value of cardiopulmonary exercise testing using percent achieved of predicted peak oxygen uptake for patients with ischemic and dilated cardiomyopathy. J Am Coll Cardiol. 1996;27: $345-52$.

58 Florea VG, Henein MY, Anker SD, Francis DP, Chambers JS, Ponikowski P, et al. Prognostic value of changes over time in exercise capacity and echocardiographic measurements in patients with chronic heart failure. Eur Heart J. 2000;21:146-53.

59 Stickland MK, Butcher SJ, Marciniuk DD, Bhutani M. Assessing exercise limitation using cardiopulmonary exercise testing. Pulm Med. 2012;2012:824091.

60 Arena R, Myers J, Aslam SS, Varughese EB, Peberdy MA. Peak VO2 and VE/VCO2 slope in patients with heart failure: a prognostic comparison. Am Heart J. 2004 Feb;147(2): 354-60.

61 Bentley DJ, Newell J, Bishop D. Incremental exercise test design and analysis: implications for performance diagnostics in endurance athletes. Sports Med. 2007;37(7):575-86.

62 Beaver WL, Wasserman K, Whipp BJ. A new method for detecting anaerobic threshold by gas exchange. J Appl Physiol (1985). 1986;60: 2020-7.

63 De Lorenzo A, Da Silva CL, Castro Souza FC, De Souza Leao Lima R. Value of the oxygen pulse curve for the diagnosis of coronary artery disease. Physiol Res. 2018 Nov 14;67(5): 679-86.

64 Belardinelli R, Lacalaprice F, Carle F, Minnucci A, Cianci G, Perna G, et al. Exerciseinduced myocardial ischaemia detected by cardiopulmonary exercise testing. Eur Heart J. 2003;24:1304-13.

65 Yasunobu Y, Oudiz RJ, Sun XG, Hansen JE, Wasserman K. End-tidal PCO2 abnormality and exercise limitation in patients with primary pulmonary hypertension. Chest. 2005; 127:1637-46.

66 Barron A, Francis DP, Mayet J, Ewert R, Obst A, Mason M, et al. Oxygen uptake efficiency slope and breathing reserve, not anaerobic threshold, discriminate between patients with cardiovascular disease over chronic obstructive pulmonary disease. JACC Heart Fail. 2016;4:252-61. 